\title{
Criterios para la lectura del Documento de Aparecida El pre-texto, el con-texto y el texto*
}

\section{Agenor Brighenti** \\ Instituto Teológico de Santa Catarina, Brasil Universidad Pontificia de México}

En el momento de elaborar estas reflexiones todavía no contamos con la publicación oficial del Documento de Aparecida, el cual fue enviado al Papa para su aprobación, una vez terminada la V Conferencia. Sólo disponemos del Documento conclusivo de la Asamblea (desde ahora, Documento), lo cual, aunque no haya alteraciones, no autoriza a hacer un análisis de su contenido. Lo que aquí nos proponemos es contribuir a preparar a los lectores para una buena interpretación y "recepción"1 del Documento.

Una lectura y recepción adecuadas del texto que está por llegar supone, entre otras cosas, determinados criterios de interpretación provenientes de las ciencias

* El autor analiza el pre-texto y con-texto del Documento conclusivo de los obispos presentado al papa para su aprobación. E1 29 de junio, Benedicto XVI autorizó su publicación después de haber sido introducidas algunas correcciones. En próximos números ofreceremos reflexiones sobre el texto oficial definitivo, sus diferencias con el aprobado en Aparecida y el significado de esas diferencias.

** Fue perito del CELAM en la Conferencia de Santo Domingo y de la CNBB en Aparecida.

1. La "recepción", como realidad eclesiológica, es un concepto de Y. Congar. Entiende por ella "el acto por el cual el pueblo cristiano reconoce que lo que ha recibido es para él y reconoce que la decisión a recibirlo es una decisión importante para su vida", cfr. "La réception comme réalité ecclésiologique", en RSPT 56 (1972), pp. 369-403, aquí, p. 370. 
hermenéuticas. La hermenéutica es la condición del ser humano. La razón es interpretativa, y se sitúa en la dialéctica entre la comprensión afinada por la explicación y la explicación afinada por la interpretación. Sin embargo, aunque la razón sea inevitablemente interpretativa y esté marcada por la subjetividad, no se puede ignorar la objetividad del texto y desvincularlo de su contexto y de sus autores. Además, es muy importante tener en cuenta que el acontecimiento de la $V$ Conferencia es mucho más amplio y complejo que el documento producido por ella. El texto es un buen texto, pero ofrece menos de lo que fue la Conferencia, menos incluso de lo que fue la Asamblea, pues, por razones que veremos a continuación, quedó por bajo de lo que aportaron los participantes². La puerta de acceso al Documento es el propio texto, pero para su interpretación y comprensión hay que situarlo en el amplio contexto de la preparación y realización de la $\mathrm{V}$ Conferencia, en cuyo seno fue producido.

Simplificando la cuestión, y evitando enfoques excesivamente académicos, ofreceremos a continuación algunos criterios contextualizados, que deben ser tenidos en cuenta en la lectura del Documento. Los agrupamos en torno a tres polos que conforman la tarea de interpretación de cualquier texto: el "pre-texto" (la coyuntura del texto), el "con-texto" (los autores o coautores del texto) y el "texto" (el documento en sî). Con todo, como ya hemos señalado, no nos quedaremos al nivel de principios teóricos, sino que trataremos de historizarlos teniendo en cuenta el "antes", el "durante" y el "después" de la V Conferencia. Para fundamentar y justificar los criterios que vamos a enumerar, aduciremos algunas citas del Documento en notas al pie de página, según la versión de la Asamblea en Aparecida.

2. A los filtros y controles en la Asamblea, hay que añadir la dificultad de que casi trescientos participantes, de tendencias y sensibilidades distintas, partiendo de cero, redacten un documento en tres semanas. De igual modo, el control al que hemos hecho referencia aparece en que ninguna de las cinco conferencias del CELAM haya sido autorizada a trabajar en base a un "Documento de Trabajo". La excepción fue la Conferencia de Medellín, lo que también explica por qué elaboró un magnífico texto. No es que los obispos sean incapaces de elaborar un buen documento, pero falta tiempo para hacer un texto mejor que los habituales. El que el documento de Aparecida sea bueno es más un milagro que el fruto de buenas condiciones de trabajo. La justificación que se da para no partir de un documento de trabajo es que, como se trata de una asamblea de obispos, si se partiera de un documento de trabajo previo, el documento final no sería ya de los autores, sino de todo el Pueblo de Dios. Y quienes trabajan en una conferencia — se dice - son los obispos — lo cual no es verdad. Más de la mitad de los participantes de la V Conferencia no eran obispos, es decir, no tenía voto, pero tuvieron voz, y fueron parte integrante y decisiva del documento final. La Conferencia de Medellín sí tuvo un documento de trabajo que sirvió de punto de partida — por lo cual se ha podido decir que que no fue un documento de obispos, sino de teólogos. ¿Y qué hay de malo en que los teólogos propongan a los obispos reflexiones proféticas e inspiradoras? De todas maneras, quizás por esa razón, en Aparecida los teólogos estuvieron más presentes y actuantes fuera que dentro de la Asamblea. 


\section{El "pre-texto" del Documento}

La cabeza piensa donde están los pies, al menos cuando se piensa de manera inductiva, buscando que el pensar tenga un impacto sobre la realidad en que se está. Eso fue lo que ocurrió en la elaboración del Documento. La coyuntura alrededor del texto lo hizo posible y trazó el camino que el lector debe recorrer para interpretarlo de manera adecuada ${ }^{3}$.

Al leer el Documento es preciso tener en cuenta dos momentos distintos del "pre-texto". El primero, el "antes" del texto, consistió en todo el proceso de preparación: la definición del tema y del lugar de realización de la V Conferencia, las innumerables reuniones preparatorias, la elaboración de textos sobre el tema en cuestión, los estudios y las contribuciones de las comunidades eclesiales y de otros sujetos, etc. El segundo momento es el "durante" del texto del Documento, el evento de la asamblea con sus celebraciones y debates, el ejercicio de la colegialidad y la fraternidad episcopales, los actos alrededor de la basílica y los procedimientos en la elaboración de un texto. El "antes" y el "durante" conforman el contexto histórico y vivencial del texto, de modo que, sin su debida explicitación y conocimiento, la tarea hermenéutica se torna imposible.

\subsection{El proceso de preparación}

Para la lectura del Documento se debe comenzar por la toma de conciencia del proceso de preparación de la V Conferencia, que influyó en la elaboración del texto final. Los varios elementos ya mencionados pertenecen al momento del "antes" del texto. No los abordaremos todos, y nos limitamos al más significativo, a saber, las contribuciones de las comunidades eclesiales y de otros organismos e instituciones de Iglesia en todo el continente, como respuesta al Documento de Participación. En Brasil, y en general en muchos otros países, esas contribuciones fueron recogidas, en primer lugar por las iglesias locales, en un segundo momento se las agrupó en las regionales de la Conferencia Nacional de Obispos (CNBB) y, finalmente, fueron recopiladas por la CNBB y enviadas al Consejo Episcopal Latinoamericano y Caribeño (CELAM).

Durante el período de preparación, y en dirección casi opuesta al espíritu de estas contribuciones, se publicaron el Documento de Participación y el texto de Sintesis de las Contribuciones Recibidas, elaborados por el CELAM. El primero, como atestiguan las contribuciones de las comunidades eclesiales y de otros organismos de Iglesia, prácticamente no fue "recibido" por la Iglesia en el con-

3. En este primer apartado no abordaremos el contexto propiamente dicho de la Conferencia de Aparecida. No hay lugar para ello en estas páginas, ni es el objetivo que nos proponemos. Lo estudiaremos en otro artículo, que ya está en elaboración. Creemos que el privilegio de haber participado en el evento como perito de la CNBB nos impone el deber de compartir lo vivido para que los lectores puedan leer mejor el texto. 
tinente. Y el segundo en gran medida no recogió, como era su función, las contribuciones de las iglesias locales. Las contribuciones del Brasil, por ejemplo, están casi ausentes en la Sintesis.

Por su parte, los delegados a la V Conferencia se comportaron, en su gran mayoría, como verdaderos delegados de sus comunidades y llegaron a la Asamblea cargados de las "alegrías y las esperanzas, de las tristezas y de las angustias" (GS 1) expresadas por su pueblo. El texto de la CNBB con las "Contribuciones de la Iglesia en el Brasil”, por ejemplo, influyó en una serie de textos previos a la Conferencia, y también circuló entre los miembros de la Asamblea, causando quizá más impacto en los delegados de otros países que entre los obispos delegados brasileños ${ }^{5}$. Además, el subsidio producido por la CNBB en su Asamblea General, que tuvo lugar durante la semana anterior a la V Conferencia, formó parte igualmente de los textos que circularon, elaborados éstos sobre todo por teólogos asesores externos, en torno a Amerindia ${ }^{6}$. La CNBB goza de gran prestigio en el continente, aun cuando sea mal comprendida e incluso temida por ciertas instancias de la Iglesia.

\subsection{Insertos en un momento de crisis}

Un segundo criterio a tener en cuenta es la postura ante el momento actual de crisis. Se temía un documento final lleno de "certezas", en un mundo de incertidumbre y en crisis de identidad personal, colectiva e institucional. Pero no ocurrió así. La V Conferencia hizo evidentes las "grandes transformaciones" por las cuales pasamos ${ }^{7}$, denunció a los que adoptan posiciones eclesiológicas y doctri-

4. Esto se notó, especialmente, cuando la Asamblea comenzó escuchando a los 22 presidentes de las conferencias episcopales del continente y a los representantes de los diversos sectores de delegados e invitados presentes. Ese momento permitió "medir el pulso de la Asamblea", y entonces se constató que era menos conservadora de lo que se esperaba. Y que, por tanto, dado el espíritu del modo proceder de quienes coordinaron la etapa de preparación de la Conferencia a nivel continental, en la Asamblea habría debate o cuando menos tensiones.

5. El grupo de obispos delegados de Brasil era bastante heterogéneo, limitación, que, sumada a la falta de figuras catalizadoras, no permitió una actuación más concertada y consensuada.

6. "Amerindia" es una red de católicos, compuesta por teólogos, agentes de pastoral y líderes laicos, presente, en grupos, en todos los países del continente, organizada por regiones y a nivel continental, y que se propone mantener viva la tradición latinoamericana y caribeña presente, entre otros espacios, en la teologia de la liberación, en las comunidades eclesiales de base, CEBs y en la memoria de los mártires de las causas sociales.

7. "Los pueblos de América Latina y de El Caribe viven hoy una realidad marcada por grandes cambios que afectan profundamente sus vidas..." (DA 33), con "consecuencias para todos los ámbitos de la vida social, impactando la cultura, la economía, la 
nales anteriores al Vaticano II $^{8}$ e invitó a los cristianos a asumir la cultura actual, pese a estar marcada por contradicciones y ambiguiedades ${ }^{9}$. Con el pretexto de que el mundo ha cambiado, ciertos sectores de la Asamblea abogaban por la necesidad de "pasar de página", sólo que querían pasar página "hacia atrás", regresando a posiciones preconciliares. La Conferencia de Aparecida, en cambio, pasó página "hacia delante", no tantas y, ciertamente no todas las necesarias, pero sí las suficientes para situarnos, como Iglesia, en el mundo de hoy y caminar juntos con toda la humanidad ${ }^{10}$.

Es sabido que el Concilio Vaticano II pasa por una crisis de "recepción", lo cual se debe principalmente a la dificultad de muchos de dejar atrás la cristiandad y entrar en la era de la modernidad, con la autonomía de lo temporal y de las ciencias, en un mundo pluralista y diversificado. La Conferencia de Aparecida, sin embargo, enterró la cristiandad, como ya lo había hecho el Concilio, acallando las voces que se hacen eco de un pasado sin retorno. La única garantía de futuro es correr el riesgo de convivir con lo que es diferente y que ya está emancipado de la tutela de la Iglesia.

\subsection{La reafirmación de la tradición latinoamericana y caribeña}

Un tercer elemento es que, contra todo pronóstico - en base, sobre todo, a la posición del Documento de Participación y del texto de Síntesis de las Contribuciones Recibidas - la Conferencia de Aparecida reafirmó y reasumió la tradición latinoamericana y caribeña. El texto final reafirmó y radicalizó la opción preferencial por los pobres ${ }^{11}$. Con Medellín reasumió las comunidades eclesiales de base (CEBs) como "célula inicial de la estructura eclesial"12. Retomó el mé-

política, las ciencias, la educación, el deporte, las artes y también, naturalmente, la religión" (DA 35).

8. "Lamentamos cierto clericalismo, algunos intentos de volver a una eclesiología y espiritualidad anteriores al Concilio Vaticano II..." (DA 109).

9. "Muchos católicos se encuentran desorientados frente a este cambio cultural... Sin embargo, el anuncio del Evangelio no puede prescindir de la cultura actual. Ésta debe ser conocida, evaluada y en cierto sentido asumida por la Iglesia, como un lenguaje comprendido por nuestros contemporáneos" (DA 499).

10. "Ser discípulos y misioneros de Jesucristo para que nuestros pueblos, en Él, tengan vida, nos lleva a asumir evangélicamente y desde la perspectiva del Reino las tareas prioritarias que contribuyen a la dignificación de todo ser humano, y a trabajar junto con los demás ciudadanos e instituciones en bien del ser humano" (DA 398).

11. "Hoy queremos ratificar y potenciar la opción del amor preferencial por los pobres hecha en las Conferencias anteriores. Que sea preferencial implica que debe atravesar todas nuestras estructuras y prioridades pastorales" (DA 410).

12. "Queremos decididamente reafirmar y dar nuevo impulso a la vida y misión profética y santificadora de las CEBs, en el seguimiento misionero de Jesús" (DA 194). "Ellas recogen la experiencia de las primeras comunidades, como están descritas en los 
todo inductivo de la lectura de la Palabra revelada y del compromiso pastoral en sintonía con los desafíos de la realidad, el método ver-juzgar-actuar de la Acción Católica ${ }^{13}$. Y reafirmó la necesidad de un cambio, a la vez de la persona y de las estructuras de la sociedad, como condición para una sociedad justa ${ }^{14}$. Fue una toma de postura impensable en la actual coyuntura eclesial, donde parecía que tomaba fuerza la tendencia eurocentrista, fuertemente preconciliar.

A diferencia de lo ocurrido en Santo Domingo, los representantes de esta tendencia que estuvieron presentes en la Asamblea llegaron a Aparecida golpeados por la crítica situación de la Iglesia en Europa, la que prácticamente agoniza ${ }^{15}$. Europa es un estado sin pueblo, sin alma, inmersa en el consumismo y empeñada en ex-culturar las últimas raíces cristianas ${ }^{16}$. Y como en aquel continente faltan las condiciones para un testimonio profético, la Iglesia se encuentra postrada, sin interlocutores. En América Latina y el Caribe, en cambio, a pesar de estar también inmersa en un contexto de crisis y con sangría de seguidores hacia otros grupos religiosos, la Iglesia abarca todavía casi el $80 \%$ de la población y cuenta con una inmensa red capilar de pequeñas comunidades vivas, de organizaciones que hacen de los pobres sujetos de una sociedad justa y solidaria. Esto hace que todavía entre nosotros la Iglesia sea la institución de mayor credibilidad e influencia en la sociedad. En esta perspectiva, contrariamente al Documento de Participación y al texto de Síntesis de las Contribuciones Recibidas, el Documento acogió la herencia de los mártires de las causas sociales, denominándolos "nuestros santos, aún no canonizados"17.

Hechos de los Apóstoles ( $c f r$. Hch 2, 42-47). Medellín reconoció en ellas una célula inicial de estructuración eclesial y foco de evangelización" (DA 193).

13. "Nos sentimos interpelados a discernir los "signos de los tiempos", a la luz del Espíritu Santo, para ponernos al servicio del Reino" (DA 33).

14. "Esta es la tarea esencial de la evangelización, que incluye la opción preferencial por los pobres, la promoción humana integral y la auténtica liberación cristiana” (DA 161). La promoción de la vida plena en Cristo, "nos lleva a asumir evangélicamente y desde la perspectiva del Reino las tareas prioritarias que contribuyen a la dignificación de todo ser humano... Urge crear estructuras que consoliden un orden social, económico y político en el que no haya inequidad y donde haya posibilidades para todos" (DA 398).

15. En países católicos como Bélgica y Francia, la asistencia dominical se reduce a unas decenas de personas de edad, y el $80 \%$ de los sacerdotes tienen más de 65 años. En las diócesis, decenas de parroquias no tienen sacerdote.

16. La primera secularización de la modernidad implicó una desconfesionalización de los valores cristianos, asumidos por la sociedad emancipada como auténticos valores humanos. Hoy se da una segunda secularización, más radical, pues implica hacer desaparecer de la cultura europea las últimas raíces del cristianismo, presente en determinados valores humanos.

17. "Queremos recordar el testimonio valiente de nuestros santos y santas y de quienes aún sin haber sido canonizados, han vivido con radicalidad el evangelio y han ofrendado su vida por Cristo, por la Iglesia y por su pueblo" (DA 98). 


\subsection{Una postura crítica frente a la globalización, aunque sin ir a las causas}

Hay un cuarto elemento del "pre-texto" a ser tenido en cuenta. Aun reconociendo valores en el actual proceso de mundialización, junto con Benedicto XVI, la Conferencia de Aparecida adoptó una postura crítica frente a la actual globalización económica que se realiza a través de la hegemonía del mercado ${ }^{18}$ en el seno del sistema neoliberal. La globalización abre nuevas posibilidades para algunos, pero cierra puertas a la gran mayoría de la población ${ }^{19}$. Es responsable de los nuevos rostros de la pobreza ${ }^{20}$, los cuales, más que de empobrecidos, son ahora de los olvidados, desechables, aquellos de quienes prescinde el mercado ${ }^{21}$.

Sin embargo, a pesar de esta postura profética crítica, no se dieron las condiciones para ir a las raíces de la exclusión y relacionarla con el sistema liberalcapitalista actual, por más que muchas comisiones y las subcomisiones temáticas insistieran en ello ${ }^{22}$. En realidad, es una postura de acuerdo a la doctrina social de la Iglesia, la cual, desde el principio, condenó acertadamente el sistema colectivista marxista, pero nunca condenó el sistema liberal-capitalista. En el fondo, se piensa que el sistema es reformable, sanable, cuando lo que urge es deslegitimarlo, pues profesa intrínsecamente, como dice Puebla, un ateísmo práctico. Se piensa que el mercado y la democracia son creaciones del capitalismo, cuando, en realidad, nacieron antes que él, y, además, éste las ha desnaturalizado. Desafortunadamente, la Iglesia no ha despertado todavía a las duras consecuencias del sistema capitalista-liberal, sobre todo en el ámbito cultural: el evidente proceso de exacerbación del individualismo, la mercantilización de las relaciones humanas y la fragmentación del tejido social. En la medida en que impide una real experiencia comunitaria, el sistema liberal capitalista a largo plazo acabará haciendo al cristianismo inviable. Esto ya está ocurriendo, en cierta medida, en Europa donde la Iglesia ya ha renunciado a buscar ser comunidad, y se ha resignado a mantener la fe en el corazón de las personas. Pero sin comunidad no hay Iglesia. Más aún, no hay fe cristiana.

18. "En la globalización la dinámica del mercado absolutiza con facilidad la eficacia y la productividad como valores reguladores de todas las relaciones humanas... [transformándola] en un proceso promotor de inequidades e injusticias múltiples" (DA 61).

19. "El Papa también señala que la globalización "comporta el riesgo de los grandes monopolios y de convertir el lucro en valor supremo" (DA 60).

20. En el número 65, el Documento menciona: las comunidades indígenas y afroamericanas, mujeres excluidas, jóvenes, desempleados, migrantes, niñas prostituidas, millones de personas y familias que pasan hambre, dependientes de drogas, víctimas de la violencia, ancianos y presidiarios.

21. "Los excluidos no son solamente 'explotados' sino 'sobrantes' y 'desechables'" (DA $65)$.

22. El influyente Don Demétrio Valentini, quien prácticamente coordinó la redacción del análisis de la realidad social en la comisión temática, vio eliminadas de manera sistemática sus reiteradas inclusiones de esta cláusula. 


\subsection{Una buena lectura de la realidad eclesial, pero sin autocrítica histórica}

Por lo que toca a la realidad eclesial, el Documento hace un buen análisis de la situación actual de la Iglesia, identificando con claridad y profecía los retos para la evangelización del continente. Presenta un listado de luces y sombras, aunque restringidas al momento presente. No hubo forma de que en el texto final entrase una autocrítica sobre la trayectoria histórica de la Iglesia en el continente. A ese respecto, el Documento de Participación se limitó a identificar las luces. El texto de Sintesis de las Contribuciones Recibidas ni siquiera hizo eso, pues simplemente ignoró el pasado. Y lo mismo hizo Aparecida. Sobre esto se elaboraron varias enmiendas al texto, pero la comisión de redacción no las recogió, no se sabe si por criterio propio o de otras instancias ${ }^{23}$. Por lo que toca a la Asamblea, quizás, aunque de modo indirecto, el Papa tuvo que ver con ello, dada su postura en el discurso inaugural. Benedicto XVI dijo que "el anuncio de Jesús y de su Evangelio no supuso, en ningún momento, una alienación de las culturas precolombinas, ni fue una imposición de una cultura extraña”.

Ante la fuerte reacción, especialmente de los indígenas y negros, el Papa, ya de regreso en Roma, reconoció que

el recuerdo de un pasado glorioso no puede ignorar las sombras que acompañaron la obra de la evangelización del continente latinoamericano... los sufrimientos y las injusticias que los colonizadores infligieron a la población indígena, frecuentemente pisoteada en sus derechos fundamentales... condenados, ya entonces, por misioneros como Bartolomé de las Casas y teólogos como Francisco de Vitoria.

Hubo sombras, pues, pero que provenían de los colonizadores, y que fueron condenadas por la Iglesia. En este contexto era muy difícil abordar la cuestión en el Documento. Pero es de lamentar que se haya desaprovechado esta oportunidad histórica para saldar la deuda de la Iglesia con los indígenas y los negros del continente. Ya ha habido peticiones de perdón, pero muy tímidas. La más explícita, aunque tardía, fue la de la CNBB, en Porto Seguro, con ocasión de la celebración de los quinientos años de evangelización en el Brasil.

\section{El "con-texto" del Documento}

Para una adecuada lectura de un texto, además del "pre-texto" hay que tener en cuenta su "con-texto", esto es, sus autores y coautores, que están estrechamente unidos al texto. Se comprende mejor un texto cuando se sabe quiénes fueron sus autores, con quiénes interactuaron y cómo trabajaron. Y no sólo eso. En la

23. Quizás no de la presidencia del CELAM, que, aunque más conservadora que la Asamblea, era mucho más abierta que la comisión de redacción, aun cuando ésta incluía a algunas personas en sintonía con la tradición latinoamericana y caribeña. 
medida en que quien lee un texto lo relee, crea nuevos sentidos.. Los "receptores" de un texto también son "con-texto" del texto. Por razones de espacio, nos limitamos aquí a los autores más directos, dejando de lado a los lectores en cuanto receptores.

\subsection{El voto de los obispos, enriquecido por la voz de los invitados}

Un primer criterio relativo al "con-texto" es tener en cuenta que se trata de un documento del magisterio de los obispos latinoamericanos y caribeños, asumido y aprobado por ellos. Eran los ûnicos con poder de voto, pero en sentido estricto el Documento no fue redactado sólo por ellos. Las conferencias episcopales de América Latina y el Caribe son asambleas sólo de obispos y, por consiguiente, ellos serían los únicos autores de los documentos por ellas producidos. Pero no es así.

En el caso de la Asamblea de Aparecida más de la mitad de sus integrantes fueron no-obispos ${ }^{24}$. No tenían voto, pero sí tenían voz. Hablaron mucho y fueron escuchados. Tan es así que algunos obispos, celosos de sus prerrogativas, se quejaron de que en las comisiones temáticas había más no-obispos que obispos. Muchos otros, por el contrario, se alegraron de esa presencia y establecieron un proceso interactivo entre todos.

Junto a esos autores obispos y no-obispos presentes en la Asamblea, al hablar del "con-texto" tampoco se pueden olvidar los millares de personas que participaron en el proceso de preparación, enviando sugerencias o preparando textos de reflexión. Y a través de sus delegados, aunque indirectamente, también fueron voces que se hicieron oír en el seno de la Asamblea. Por eso, el Documento es un texto del magisterio de los obispos, pues fueron ellos quienes lo aprobaron. Pero no fueron sólo ellos quienes lo produjeron, y, por lo tanto, no son sus úni-

24. Los 268 participantes de la Asamblea se hicieron presentes en las categorias de miembros, invitados, observadores y peritos. Unicamente los miembros - los cardenales (entre ellos, doce latinoamericanos y caribeños), arzobispos y obispos - tuvieron derecho a voz y voto, en total 123. Los demás, sólo tuvieron voz. Los invitacios eran obispos, presbíteros, diáconos permanentes, religiosos y religiosas, así como laicos representantes de movimientos y otros organismos. Los observadiores eran representantes de otras Iglesias o denominaciones religiosas. Los peritos, en número de 15, eran teólogos que colaboraron en la reflexión y elaboración del Documento. Hay que mencionar la presencia de miembros de la Curia Romana (en número de 17), entre ellos cinco cardenales latinoamericanos (cuatro se hicieron presentes); dos presidentes, obispos e invitados de las conferencias episcopales de Canadá, los Estados Unidos, España, Portugal, África, Europa y Asia (en número de 12); de superiores religiosos mayores (5); de la Conferencia de Religiosos de América Latina y el Caribe CLAR (3); de movimientos eclesiales (Neocatecumenal, Shalom, Comunión y Liberación, Schoenstatt, Sodalicio) y de organismos de ayuda (6). 
cos autores. Lo mismo habría que decir, por cierto, del Concilio Vaticano II, que hubiese sido impensable sin las intuiciones de los movimientos que lo prepararon y los teólogos que lo procesaron. No es exagerado afirmar, por lo tanto, que el Documento es un texto de la Iglesia de América Latina y el Caribe, acogido y aprobado por los obispos, pero elaborado por una asamblea no compuesta solamente de obispos, y, además, en interacción con una multitud de personas que participaron en el proceso de la preparación de la V Conferencia. En este contexto debe ser leído el texto.

\subsection{Una Asamblea en interacción con actores externos}

Para entender el texto también hay que tener presente que la Conferencia de Aparecida fue la primera asamblea realizada en la época del teléfono celular e internet. Por más que se defendiese el recinto de la Asamblea del acceso de personas extrañas, desde afuera se podía acompañar casi simultáneamente lo que acontecía dentro de ella. Bastaba con que alguien dejase un teléfono o un notbook conectado a internet. Además, fue la primera Asamblea realizada en un local público, el Santuario de Aparecida, al que diariamente acuden miles de personas, y más de sesenta mil cualquier fin de semana. De este modo, los obispos y demás delegados de la Conferencia estuvieron en contacto directo con los peregrinos, que expresan así la religiosidad popular.

Por otra parte, el alojamiento de los participantes de la Asamblea en hoteles cercanos a la basílica permitió el contacto con actores externos, entre ellos teólogos asesores de conferencias episcopales nacionales y un significativo grupo de teólogos y personas de otros campos de las ciencias reunidos por Amerindia. Con estos actores, también por primera vez, a diferencia de las conferencias de Puebla y Santo Domingo, los teólogos que estaban fuera de la Asamblea no trabajaron en forma clandestina. Por el contrario, gozaron de la anuencia de la presidencia del CELAM. Juntamente con los teólogos llevados por las conferencias nacionales, Amerindia organizó varios encuentros de teólogos con obispos, sacerdotes, religiosos y laicos participantes, por separado y en conjunto, para diseñar estrategias, debatir determinadas cuestiones y lograr determinados acuerdos. Fueron innumerables los textos redactados por estos teólogos vinculados a Amerindia y otros asesores. Y fueron centenares las enmiendas elaboradas para mejorar el texto, en gran medida recogidas por la Asamblea a través de la proposición de sus miembros ${ }^{25}$.

25. Entre los miembros de Amerindia, coordinados por Pablo Bonavía, merece destacarse el excelente e incansable trabajo del teólogo chileno P. Sergio Torres, gran responsable del puente establecido entre la entidad y el CELAM. Sobresalió, igualmente, por su poder de convocatoria de los participantes de la Asamblea, a quienes conoció en gran medida en sus viajes de contacto por el continente, efectuados en los meses anteriores a la Asamblea de Aparecida. Tampoco se puede dejar de registrar la valiosa 
En el "con-texto" tampoco se puede dejar de mencionar la fuerza simbólica del Foro de Participación de la V Conferencia, organizado por organismos de pastoral de la Iglesia en el Brasil. Fueron tres iniciativas significativas: el seminario latinoamericano de Teología, celebrado en Pindamonhangaba, bajo la coordinación del Consejo Nacional de los Laicos (con la participación de personas de todo el Brasil y de 16 países latinoamericanos y caribeños y de Europa, que fue transmitido por Internet con asistencia en 27 salas en el país); la Romería de las CEBs, de la Pastoral Obrera y de la Pastoral de la Juventud, desde Roseiras hasta la basílica de Aparecida (de la medianoche a las ocho de la mañana, con la participación de más de cinco mil personas); y la Tienda de los Mártires, montada en las márgenes del río Paraíba, con celebraciones, oficio de las comunidades, reflexiones y misa diariamente, durante las tres semanas de la Asamblea (la comunidad local se hizo presente y varios obispos presidieron la eucaristía, como el vicepresidente de la CNBB, Don Luís Vieira; el último día con la grata sorpresa de la presencia del Padre Zezinho) ${ }^{26}$.

\subsection{La autoafirmación de una conferencia latinoamericana y caribeña}

Con el advenimiento de los sinodos continentaies, parecía que las conferencias generales de obispos de América Latina y el Caribe irían a formar parte de un pasado glorioso. Sin embargo, para celebrar los cincuenta años de la primera Conferencia de Río de Janeiro se mantuvo, aunque con dos años de retraso, el modelo de Conferencia - sólo que, al contrario de las anteriores, ésta debería tener lugar en Roma. Pero el CELAM, con el apoyo de casi todos los cardenales que viven y trabajan en el continente, insistió en que se realizase en nuestro suelo. Y así ocurrió. En seguida comenzó la etapa de preparación, por cierto con poca

contribución, entre los 28 presentes, de teólogos como Ronaldo Muñoz, Pablo Richard, Gregorio Iriarte, Paulo Suess, José Oscar Beozzo, Benedito Ferraro, Vera Bombonato, etc., y de otros que contribuyeron desde sus países, como Gustavo Gutiérrez, Jon Sobrino, J. B. Libânio... De todas formas, ¿qué institución puede darse el lujo de dejar fuera de un evento tan importante, como la Asamblea de Aparecida, a sus mejores pensadores?

26. Fue muy difícil la puesta en práctica de estas tres iniciativas, en lo que se tuvo que implicar el CELAM, la Curia Romana, la CNBB y la arquidiócesis de Aparecida. Para que saliesen adelante fue muy importante la persistencia de José Oscar Beozzo y Benedito Ferraro, entre otros. Se hablaba de eventos paralelos o de presión sobre la Asamblea. En realidad, fueron iniciativas de acompañamiento impregnadas de mística y profecía. En todo caso, sea por la fuerza de la oración, sea por la fuerza simbólica de los acontecimientos, el hecho es que tres temas relacionados con estas iniciativas, casi tabúes antes de la Asamblea, terminaron estando muy presentes en el Documento: las CEBs, las intuiciones de la teología latinoamericana y caribeña y el reconocimiento de los mártires de las causas sociales, "nuestros santos todavía no canonizados". Valió la pena el sacrificio y el riesgo. 
impronta latinoamericana y caribeña, y con algunas posturas preconciliares, en especial en la eclesiología, la cristología y la misionología. Las comunidades que participaban en la preparación y otros organismos eclesiales hicieron oír su voz de desaprobación y reafirmaron la perspectiva conciliar y de la tradición latinoamericana y caribeña. Surgieron, entonces, los filtros y recortes a la voluntad de la mayoría, como se puede comprobar en el texto de Síntesis de las Contribuciones Recibidas, al que no se quiso denominar "documento", ni mucho menos "documento de trabajo". Hubo, igualmente, filtros en la designación de los "invitados" de los diversos países, sobre todo en lo referente a los teólogos. Y también hay que tener presente que a la Asamblea llegaron 17 miembros de la curia romana.

Sin embargo, para sorpresa de los sectores más abiertos —y mucho más para los conservadores - la Asamblea se hizo oír, marcó la pauta y reivindicó sus esperanzas y sueños. Se esperaba, un debate acalorado, pero no lo hubo, debido sobre todo al tono conciliador de la presidencia del CELAM. Y es que son otros tiempos. Hoy se evita la confrontación. Se calculan las fuerzas y se cede, sea para no salir perdedor, sea - lo que es más honesto - para preservar la unidad. Y así todos terminan ganando, pues es posible avanzar.

\subsection{Las puertas abiertas por Benedicto XVI en su Discurso Inaugural}

Otro factor importante para que la Asamblea pudiese reafirmarse en la perspectiva de la tradición latinoamericana y caribeña fue el Discurso Inaugural de Benedicto XVI. Sorprendentemente, el Papa no ayudó a los sectores conservadores, más bien abrió puertas a los sectores más comprometidos con las causas de los pobres. Benedicto XVI comenzó hablando de la fe cristiana que viene "animando la vida y la cultura de nuestros pueblos" desde hace más de 500 años. Hoy, dijo, la Iglesia en América Latina y el Caribe enfrenta "serios desafíos", como una globalización sin equidad, y "un cierto debilitamiento de la vida cristiana en el conjunto de la sociedad" y de la propia "pertenencia a la Iglesia católica". Eso pone "en juego su desarrollo armónico y la identidad católica". Estamos ante una "encrucijada", expresó el Papa, que nos remite a Jesucristo, de cuya fuente "podrán surgir nuevos caminos y proyectos pastorales creativos". Es Él quien nos da vida plena, lo que no es intimismo y fuga del mundo, al contrario. Como discípulos y misioneros nos impulsa a "promover una cultura de la vida". Esta tarea implica "un programa general", respaldado por un "consenso moral de la sociedad", según la recta ratio y no las ideologías, pues "las estructuras justas son una condición sin la cual no es posible un orden justo en la sociedad". El trabajo político "no es competencia inmediata de la Iglesia", que debe respetar "una sana laicidad", porque, de lo contrario, perdería la independencia en su "vocación fundamental de orientar las conciencias, ofrecer una opción de vida más allá de lo político" y de ser "abogada de la justicia y de la verdad". 
Para el Papa, otros campos prioritarios de la acción son la familia, los presbíteros, los religiosos(as) y consagrados(as), los laicos y los jóvenes, y la pastoral vocacional. El texto concluye con una bella oración, inspirada en la experiencia de fe de los discípulos de Emaús, invitando a Jesús a quedarse con nosotros, en especial, "con aquellos que en nuestras sociedades son más vulnerables; quédate con los pobres y humildes, con los indígenas y afroamericanos, que no siempre han encontrado espacios y apoyo para expresar la riqueza de su cultura y la sabiduría de su identidad".

\section{El "texto" del Documento}

El "pre-texto" y el "con-texto" nos llevan al Documento de Aparecida. Es cierto que, a fin de cuentas, lo que debe ser "recibido" es el acontecimiento de la $V$ Conferencia, pero lo que ha quedado para ser interpretado es el rico texto que produjo la Asamblea. Como nuestro propósito es ofrecer criterios de lectura, no vamos a presentar el contenido del texto $-\mathrm{y}$ ya dijimos que no disponemos del texto oficial. Nos limitaremos a llamar la atención sobre algunas características del texto que deben ser tomadas en cuenta en su lectura e interpretación con vistas a su "recepción".

\subsection{Un texto fruto de acuerdos, no siempre consensuados}

Documentos como el de Aparecida, por ser fruto de una asamblea pluralista y de la convergencia de diversas tendencias y sensibilidades, inevitablemente están marcados por contradicciones. Pero las proposiciones, distintas, no siempre tienen el mismo peso. Hay afirmaciones hegemónicas que recorren todo el documento y forman parte del espíritu del texto, y hay afirmaciones residuales, más periféricas, que entraron en el texto para que otras posiciones pudieran ser mantenidas. Pero no expresan el espíritu del texto.

En líneas generales el documento es bastante homogéneo, y no presenta mayores dificultades al lector. Sí es cierto que, en el tratamiento de algunos temas, no hubo manera de evitar compromisos entre la mayoría y una minoría que controlaba ciertas instancias de decisión, pues no todo fue votado en plenario desde el inicio. Algunos ejemplos. Para que las comunidades eclesiales de base pudiesen entrar en el Documento como "lugar de estructuración inicial de la Iglesia", el texto incluye también la relevancia de los movimientos. Para que se pudiese volver al método ver-juzgar-actuar, se tuvo que aceptar que el análisis del ver comenzara con una profesión de fe. Para que la mujer pudiese aparecer destacadamente como protagonista en la Iglesia y en la sociedad, también se tuvo que afirmar su papel en el hogar, como madre de familia. Para que se pudiese reconocer el profetismo y la inserción de la vida religiosa en los medios más pobres 
— "elemento decisivo para la misión"27 —, se tuvo que reconocer la importancia de las "nuevas comunidades de vida", etc.

Estos contrapuntos son claramente residuales y no reflejan el espíritu del texto, tal como el mismo Documento se encarga de precisar. Por ejemplo, al hablar de la importancia de los movimientos, el texto anota que "no siempre se integran en la pastoral parroquial y diocesana" 28 . Por lo que toca al discernimiento de la realidad - la necesidad de partir del plan de Dios - , afirman los obispos que "nos sentimos interpelados a discernir los 'signos de los tiempos', a la luz del Espíritu Santo, para ponernos al servicio del Reino" ${ }^{29}$. Por lo que toca a la mujer, como "ama de casa", el texto insiste en que "innumerables mujeres, de toda condición social, no son valoradas en su dignidad, quedan con frecuencia solas y abandonadas, no se les reconoce suficientemente su abnegado sacrificio e incluso heroica generosidad en el cuidado y educación de los hijos ni en la transmisión de la fe en la familia, no se valora ni promueve adecuadamente su indispensable y peculiar participación en la construcción de una vida social más humana y en la edificación de la Iglesia... Es necesario en América Latina superar una mentalidad machista" 30 .

Y prosigue: "urge escuchar el clamor muchas veces silenciado de las mujeres que son sometidas a muchas formas de exclusión y de violencia en todas sus formas y en todas las etapas de su vida... Urge que todas las mujeres puedan participar plenamente en la vida eclesial, familiar, cultural, social y económica, creando espacios y estructuras que favorezcan una mayor inclusión" 31.

Por lo que toca a las "nuevas comunidades de vida", el Documento afirma que "el Espíritu Santo sigue suscitando nuevas formas de vida consagrada en la Iglesia, las cuales necesitan ser acogidas y acompañadas... con un discernimiento serio y ponderado sobre su sentido, necesidad y autenticidad" 32 .

En conclusión, movimientos, familia y nuevas comunidades de vida no son los sujetos eclesiales hegemónicos del Documento de Aparecida, tal como se temía antes de la Asamblea. Al contrario, las iglesias locales, organizadas en parroquias, son las que necesitan ser renovadas en sus estructuras mediante su sectorización en áreas menores. Y dentro de los sectores, hay que dar un nuevo impulso a las CEBs, organizando en su seno "comunidades de familias" ${ }^{3}$.

\footnotetext{
27. Cfr DA 232.

28. Cfr. DA 112.

29. Cfr. DA 33.

30. Cfr. DA 472.

31. Cfr. DA 473.

32. Cfr. DA 238.

33. Cfr. DA 384.
} 


\subsection{La recuperación del método inductivo de la Gaudium et Spes}

Una segunda característica del texto es que está estructurado según el método ver-juzgar-actuar: "La vida de nuestros pueblos hoy" (primera parte), "La vida de Jesucristo en los discípulos misioneros" (segunda parte) y "La vida de Jesucristo para nuestros pueblos" (tercera parte).

Esta recuperación del método inductivo de la Gaudium et spes fue uno de los puntos de tensión en la Asamblea entre una mayoría que lo reivindicaba y una minoría que se resistía. El Documento de Participación ignoró este método, que ha sido ampliamente practicado por la Iglesia en América Latina y el Caribe, acostumbrada a comenzar con un discernimiento de la realidad del mundo y de la Iglesia, confrontarlo con las luces de una revelación contextualizada en el hoy $\mathrm{y}$, desde ahí, encontrar directrices y respuestas pastorales. Por eso las iglesias locales reaccionaron ante ese documento. Y el texto de Sintesis de las Contribuciones Recibidas tuvo que dar la impresión de volver a él, aunque lo hizo en una formulación que lo diluía: "ver a la luz del proyecto del Padre", "juzgar a la luz de la fuente de vida, que es el Hijo" y "actuar en el Espíritu, que nos empuja a ser discípulos misioneros". El modo de proceder seguía siendo claramente deductivo. La realidad no era escuchada en su autonomía ni incidía en ningún momento en la captación de la revelación, que es lo que permite actualizar el mensaje en el contexto actual.

Volviendo a la Asamblea, se reafirmó la necesidad de rescatar el método, pero en su primera versión, elaborada por la comisión de redacción, el esquema general del Documento, era totalmente deductivo. Hubo fuertes reacciones antes de ser presentado al plenario, y fue abortado por la presidencia del CELAM. La segunda redacción, hecha de prisa con base a una propuesta del presidente del CELAM, que recogía las contribuciones de la Asamblea, retomó el método verjuzgar-actuar. Fue votada y aprobada.

Por lo que toca a la secuencia del método, la primera y segunda redacción del Documento mantuvieron esta estructura metodológica. Con todo, en la tercera redacción, el primer capítulo de la segunda parte — una especie de profesión de fe-, relativa al "juzgar", fue desplazado a la primera parte dedicada al "ver". Quedó convertido, así, en un primer capítulo con anterioridad al ver la realidad social y eclesial. Y así quedó. Ni siquiera el recurso de petición de importancia, presentado por presidentes de conferencias episcopales, conforme a lo previsto por el reglamento, consiguió que fuese puesto a votación. También se había invertido el orden dentro del "ver", analizando primero la realidad de la Iglesia y después la del mundo. Pero esto sí se logró invertir, y recuperar el orden original.

Es evidente que esto no pone en peligro el método ver-juzgar-actuar, pero sus adversarios pueden reinterpretarlo y diluirlo: se empieza, sí, viendo la realidad, pero como personas de fe, lo que significa en definitiva mantenerse en el ambiente 
de cristiandad, de irrespeto a la autonomía de lo temporal y de las ciencias metodológicamente a-religiosas, y de miedo al mundo y a lo diferente. En realidad, esta postura confunde realidad y diagnóstico de la realidad.

En medicina, los exámenes que se hacen al paciento son pruebas, datos de laboratorio, de radiografías, de ultrasonidos, etc., basados en un instrumental técnico que, aunque no sea neutro, actúa con independencia del médico. El diagnóstico, en cambio, sí depende del médico. Compara los datos de los exámenes realizados al paciente con los datos ideales de una persona sana, y saca conclusiones. El diagnóstico es resultado final, no punto de partida de un proceso de investigación de la realidad, conocida a través de medios específicos, comparada con un referente ideal. Imaginemos qué ocurriría si un médico sacara conclusiones sin examinar al paciente o que pidiera examinar al paciente después de haber hecho el diagnóstico.

Argumentan algunos que ir a ver la realidad con las ciencias es correr el riesgo de ideologizarla. Por eso, sostienen, se debe ir a ella con fe, con teología. Pero la realidad no es objeto inmediato de fe y de teología. Si se la observa inmediatamente desde ellas quedará igualmente ideologizada, espiritualizada. En teología, el conocimiento de la realidad sólo puede ser mediado por las ciencias que se ocupan de la realidad, y es evidente que así como existen teologías, de igual modo existen ciencias. La solución no consiste en renunciar a las ciencias, sino en establecer criterios para escoger el instrumental analítico más adecuado para entender la realidad. Y aquí sí entra la fe. Pero entra como un presupuesto para escoger un método adecuado, no para sustituir a la ciencia y su autonomía.

\subsection{Los grandes ejes o temas transversales del Documento}

Para la comprensión del Documento es importante conocer las razones de la contradicciones del texto y su estructuración, conforme al método ver-juzgar-actuar. Pero también es importante conocer sus grandes ejes o temas transversales. Ellos dan homogeneidad al texto, haciendo de él un todo, si no enteramente armónico, sí al menos lógico. Veamos los principales:

Vida en abundancia en un mundo bueno, aunque globalizado y excluyente. El tema de la Vida, central en el mensaje evangélico, la "vida en abundancia" que Jesús vino a traer, en cuanto presencia del Reino de Dios en la historia, constituye el núcleo del tema y del texto del Documento. La vida es abordada en sentido amplio - la vida plena de Dios, "en el hombre todo y en todos los hombres", en el respeto y el cuidado de la biodiversidad del planeta. La globalización actual amenaza la vida de las personas y de la naturaleza. En el Documento, la vida humana es defendida desde el inicio hasta la muerte natural. Y junto a la vida, aparece la defensa de la biodiversidad, expresión del amor de Dios en toda la obra de la creación, la que debe ser "cuidada" y "usada", antes que poseída, para 
la promoción de la vida de todos. Urge trabajar por un mundo incluyente de los excluidos y respetuoso de la naturaleza, la casa de todos.

Discípulos misioneros de Jesucristo. El don de la vida en la obra de la creación y, dentro de ella, el don de la vida de los seres humanos, hechos hijos e hijas de Dios en el Hijo, creados a su imagen y semejanza, es un regalo para ser compartido y que debe transformarse en misión. Jesús, al mismo tiempo que nos hace discípulos suyos, nos envía a defender y promover la vida de todos, expresión del reino de Dios. Se trata de un discipulado misionero. La vocación al discipulado es "con-vocación" a la misión.

Discípulos misioneros en la Iglesia, sacramento del reino. El discipulado misionero no es una tarea aventurera y voluntarista de personas dispersas, sino que se lleva a cabo en el seno de una comunidad concreta, su Iglesia. La "vocación al discipulado misionero es 'con-vocación' a la comunión en su Iglesia" ${ }^{44}$, dice el Documento. Por eso, el núcleo de su mensaje es una Iglesia en estado permanente de misión, compuesta de discípulos que, con la alegría del llamado, se convierten en defensores y promotores de la "vida en abundancia" que Jesús vino a traer al inaugurar el reino.

Una Iglesia, animada por el Espíritu, comunidad de pequeñas comunidades. La vivencia y experiencia de comunión en la Iglesia exige comunidades de tamaño humano, cuyo modelo son las CEBs. Para ello es insustituible la renovación de las estructuras de la parroquia, por medio de su "sectorización en unidades menores" 35 , y la constitución, dentro de los sectores, de "comunidades de familias" para fomentar la vida en comunidad y responder a sus problemas concretos ${ }^{36}$.

Discípulos misioneros en una Iglesia inserta en el mundo. La misión lleva al "corazón del mundo". "No es una fuga hacia el intimismo o hacia el individualismo religioso, tampoco un abandono de la realidad urgente de los grandes problemas económicos, sociales y políticos de América Latina y del mundo y, mucho menos, una fuga de la realidad hacia un mundo exclusivamente espiritual" (DI Benedicto XVI) ${ }^{37}$. De ahí la tarea prioritaria de contribuir con otros en "la dignificación de todo ser humano, y a trabajar junto con los demás ciudadanos e instituciones en bien del ser humano... las necesidades urgentes... [nos llevan a colaborar] con otros organismos o instituciones para organizar estructuras más justas en los órdenes nacionales e internacionales" ${ }^{\prime 3}$.

En un mundo predominantemente urbano. Hoy el $80 \%$ de la población de América Latina y el Caribe vive en la ciudad. "Las grandes ciudades son labo-

34. DA 171.

35. DA 384 .

36. Ibíd.

37. DA 163.

38. DA 398. 
ratorios de la cultura contemporánea" ${ }^{39}$, con un nuevo lenguaje que se extiende también al mundo rural ${ }^{40}$. "El anuncio del Evangelio no puede prescindir de la cultura actual. Ésta debe ser conocida, evaluada y, en cierto sentido, asumida por la Iglesia" 41 .

\subsection{Las novedades del Documento}

La grata sorpresa del Documento es que la Iglesia en América Latina y el Caribe no "pasó página" hacia atrás. Reafirmó la opción por los pobres, las CEBs, el método ver-juzgar-actuar, las intuiciones fundamentales de la teología latinoamericana y caribeña, las transformaciones estructurales de la sociedad como integrante de la misión evangelizadora, el testimonio y la santidad de los mártires de las causas sociales, etc. Eso, por sí solo, en la difícil coyuntura actual, tanto de la Iglesia como de la sociedad, ya sería una gran novedad. Con todo, aún fue mayor sorpresa que el Documento haya "pasado página" hacia delante. $\mathrm{Al}$ menos cinco puntos merecen mención.

Una Iglesia en estado permanente de misión. El Documento no habla de discípulos "y" misioneros sino de "discípulos misioneros", porque el discipulado es seguimiento de Jesús en cuanto es continuación de su obra. La misión "no es una tarea opcional, sino parte integrante de la identidad cristiana" 42 . "La comunión es misionera y la misión es para la comunión" ${ }^{43}$. Por lo tanto, la misión no es campaña, es un estado del ser cristiano. Con esto, la propuesta de la "misión continental" perdió fuerza, en la medida en que, si llega a acontecer, será continental únicamente en cuanto sea asumida y llevada a cabo en todas las iglesias locales. No hay Iglesia fuera de las iglesias locales ${ }^{44}$. Por ende, una misión por encima de ellas sería antieclesial.

Una misión no exclusiva, en perspectiva mundial. La promoción de la "vida en abundancia" no es una misión exclusiva de la Iglesia, sino que debe ser llevada a cabo en colaboración "con otros organismos o instituciones para organizar estructuras más justas en los órdenes nacionales e internacionales" ${ }^{45}$. Esto es así, porque, por un lado, la Iglesia no tiene el monopolio de la caridad, la justicia y la paz y, por otro, en la historia concreta, sólo serán posibles, en la medida en que sean el resultado de una acción concertada de todas las "personas de buena voluntad" a un nivel global.

\footnotetext{
39. DA 528.

40. DA 529 .

41. DA 499.

42. DA 159.

43. DA 177

44. Cfr. DA 180.

45. DA 398.
} 
La pobreza como mundo de la insignificancia. Entre los rostros que sufren, el Documento nombra las comunidades indígenas y afroamericanas, mujeres excluidas, jóvenes, desempleados, migrantes, niñas prostituidas, millones de personas y familias que pasan hambre, dependientes de las drogas, víctimas de la violencia, ancianos y presidiarios. Para el Documento, "los excluidos no son solamente 'explotados', sino 'sobrantes' y 'desechables'”, 46 , no son sólo empobrecidos. Es el pobre como insignificante, de los cuales prescinde el mercado. Como no consumen, sobran, perturban. Esta inclusión de los "desechables" implica reconocer y denunciar un cambio estructural de la sociedad, en la medida en que, en sus estructuras actuales, no caben aquéllos.

Los que se van para otros grupos cristianos, no es tanto que quieran salirse de la Iglesia, sino que están buscando sinceramente a Dios ${ }^{47}$. Los motivos no son doctrinales, sino vivenciales; no son dogmáticos, sino pastorales; no son teológicos, sino metodológicos de nuestra Iglesia ${ }^{48}$. Consecuentemente, la solución no consiste en disputarse el mercado, porque "la Iglesia crece no por proselitismo sino por atracción... de la fuerza de su amor"49. Y constata que "donde se establece el diálogo diminuye el proselitismo" ${ }^{50}$. Por eso, la Iglesia católica debe reforzarse alrededor de cuatro ejes: una experiencia religiosa personal, la vivencia comunitaria, la formación bíblico-doctrinal y el compromiso misionero de toda la comunidad ${ }^{51}$.

El protagonismo de la mujer. El Documento de Santo Domingo había proclamado el "protagonismo de los laicos" en la evangelización. Aparecida proclama el protagonismo de la mujer. El Documento constata que "tradicionalmente, debemos reconocer que un porcentaje significativo de ellos [varones] en América Latina y El Caribe, se han mantenido más bien al margen de la Iglesia" y que eso "cuestiona fuertemente el estilo de nuestra pastoral convencional"52. Por ello hay que "favorecer en la vida de la Iglesia la activa participación de los varones" 53. Sin embargo, entre las acciones pastorales también urge "impulsar la organización de la pastoral de manera que... promueva el más amplio protagonismo de las mujeres", garantizando "la efectiva presencia de la mujer en los ministerios que en la Iglesia son confiados a los laicos, así como también en las instancias de planificación y decisión"54.

46. DA 65.

47. Cfr. DA 241.

48. Ibíd.

49. DA 174.

50. DA 249.

51. Cfr. DA 242.

52. DA 480.

53. DA 482.

54. DA 477. 


\section{Conclusión}

Como se puede ver, la V Conferencia es más que el Documento de Aparecida. Éste es un texto que, para ser leído y "recibido" en toda su riqueza, necesita ser puesto en estrecha relación con su "pre-texto" y su "con-texto". En ellos se encuentra el espíritu del texto, sin el cual, el Documento se vuelve letra muerta.

Ciertamente, contamos con una fuente inspiradora y directrices audaces. Serán el alma de la acción evangelizadora en el continente al menos durante los próximos diez años, cuando, allá por el año 2018, en el cincuentenario de Medellín, podrá realizarse la VI Conferencia, en lo que ya mostró interés la Asamblea de Aparecida. Todo dependerá de la decisión con que Aparecida "sea recibida" en la práctica, poniendo a producir sus directrices en una acción evangelizadora concreta.

Tenemos entre manos una rica fuente de reflexión que podrá generar acciones capaces de hacer que la Iglesia sea, realmente, sacramento de la eternidad en la precariedad del tiempo presente. Es un texto que hace pensar, como hacen pensar las siguientes frases — una especie de Decálogo de Aparecida - que dejamos resonar en la mente del apreciado lector.

"La vocación al discipulado misionero es con-vocación a la comunión en su Iglesia" (DA 171).

"La Iglesia crece no por proselitismo sino por atracción... de la fuerza de su amor" (DA 174).

"La comunión es misionera y la misión es para la comunión" (DA 178).

"Los laicos y laicas son personas de la Iglesia en el corazón del mundo, y personas del mundo en el corazón de la Iglesia" (DA 225).

"Mucha gente que pasa a otros grupos religiosos no está buscando salirse de nuestra Iglesia sino que está buscando sinceramente a Dios" (DA 241).

"Donde se establece el diálogo ecuménico diminuye el proselitismo" (DA 249).

"La opción preferencial por los pobres está implícita en la fe cristológica" (Benedicto XVI, DA 406).

"La mentalidad machista ignora la novedad del cristianismo, que reconoce y proclama la igual dignidad y responsabilidad de la mujer respecto al hombre" (Benedicto XVI, DA 472).

"La Iglesia está convocada a ser abogada de la justicia y defensora de los pobres" (DA 409).

"América Latina y el Caribe deben ser no sólo el continente de la esperanza sino que además deben abrir caminos hacia la civilización del amor" (DA 556). 